\title{
Asbestos induced toxicity: in vitro different effects of different fibres.
}

\author{
S.DiVALERIO $^{1}$, D.RAMINI ${ }^{1}$, E.MENSÀ ${ }^{1}$, F.FAZIOLI ${ }^{1}$, \\ D.MARZIONI $^{2}$, A.F.GUALTIERI ${ }^{3}$, A.PUGNALONI ${ }^{*}$
}

${ }^{1}$ Dep. Molecular and Clinical Sciences, Dep. Experimental Clinical Medicine ${ }^{2}$, Università Politecnica delle Marche. Via Tronto 10/A 60020 Torrette, Ancona, Italy. (silviadivalerio@tiscali.it; debby.ramini@gmail.com; emanuela.mensa@gmail.com; f.fazioli@univpm.it; d.marzioni@univpm.it; *correspondance: armanda.pugnaloni@univpm.it).

${ }^{3}$ Chemical and Earth Sciences Department, University of Modena and Reggio Emilia, Via G.Campi 103,1 41125 Modena, Italy (alessandro.gualtieri@unimore.it). Asbestos exposure and malignant lung disease are epidemiologically associated. Mineral fibres are still objects of multidisciplinary and intensive investigations as their cyto and genotoxic damages pathways remain poorly understood. Methods

Human mesothelial cells (MeT5A) were exposed to mineralogically characterized asbestos fibres: UICC chrysotile, widely used in the production of asbestos containing matherial; UICC crocidolite, well known for its carcinogenic power; erionite from Jersy Nevada (USA) [1] , chrysotile from Valmalenco (Central Alps, Italy) [2,3], both naturally occurring and airborn asbestos fibres. Citotoxic and genotoxic effects were investigated by MTT test and DNA Double-Strand Breaks [4] respectively and compared.

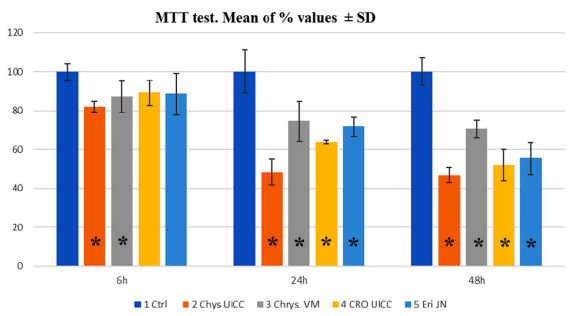

Figure1: MeT5A cells viability of control and fibres treated cultures at time points. (*) Bonferroni's $\mathbf{t}$ test $\mathbf{p}<\mathbf{0 . 0 5}$.

\section{Discussion and Results}

Both MTT test (Fig.1) and immunocytochemical detection of phosphorilated Histone $\mathrm{H} 2 \mathrm{AX}$ indicated cytotoxicity and genotoxic cancerogen potential of all fibres, including airborn fibres from natural expositions, related to their chemical and structural features [3]

[1] Pollastri et al. (2016) Chemosphere, 164, 547-557. [2] Turci et al. (2010) J. Toxicol. Environ. Health A, 73, 368377. [3] Gualtieri (2018) Toxicol. App. Pharmacol. 361, 8998. [4] Msiska et al. (2010) Am J Respir Cell Mol Biol. 43, 210-219. 